\title{
FORUM
}

\section{On Teaching Demography: Some Non-Traditional Guidelines}

Thomas K. Burch

Adjunct Professor

University of Victoria

Victoria, British Columbia, Canada

\section{Introduction}

I am grateful to Frank Trovato for the opportunity to discuss some of my recent writings on scientific methodology - on the relations among theory, models, and data - and on their implications for the teaching of demography. I am particularly pleased to get the reactions of such distinguished panellists. I am confident that by the end of the session, my thinking will have been clarified and, where necessary, corrected, and that I shall go away with new insights. These are difficult issues on which there seldom is consensus. Only occasionally do I have a sense that I have got it right.

I have always felt that demography needed more and better theory. Until just a fw years ago, I attributed the status of theory to simple neglect and to lack of sufficient interest - an opportunity cost, one might say, of demography's heavy emphasis on data, techniques, and empirical description [Burch, 1996]. I now believe that the problem goes deeper, and is due to the influence of a misleading philosophy of science that has dominated $20^{\text {th }}$ century empirical social science in general and demography in particular. This view is the logical empiricism of Ernest Nagel and Carl Hempel, combined with the ideas of Karl Popper on falsification, and with deeper roots among scientists of the $19^{\text {th }}$ [for example, Ernst Mach] and early $20^{\text {th }}$ centuries [for example, Karl Pearson]. 
Thomas K. Burch

\section{Logical Empiricism}

The central difficulty lies in logical empiricism's view of the nature of theory and its relations to empirical data. In the logical empiricist program, it is empirical generalisations or 'laws' that provide the foundation for theoretical propositions, arrived at by a process of induction - from particular cases to more general theory. The process can go through several levels, from empirical generalisations to so-called 'middle-range' theory, up to the most general and abstract theory. The relations between empirical data on the one hand and theoretical propositions on the other are purely logical. A valid proposition is one that is consistent with the data.

Explanation of a phenomenon, in this system, is achieved by subsuming it under some general law - thus the term the 'covering law' approach to explanation.

In many versions of logical empiricism and frequently in research practice, an empirical generalisation or a theoretical proposition will be rejected ['falsified'] by the discovery of empirical data that do not support the generalisation exceptions, 'counter-examples,' negative findings, etc. A classic case in demography is Coale's rejection of demographic transition theory due in part to exceptions discovered in his research on the history of European fertility decline.

A central feature of the logical empiricist approach is that theory is a superstructure derived from and therefore limited by empirical findings. In demography, this feature finds expression in the heavy reliance on statistical models, which have no place for unmeasured [directly or indirectly] variables.

Among the many difficulties with this approach identified by scientists and by philosophers of science, two stand out:

1] There are few broad empirical generalisations and hardly any universal generalisation in social science, so that the foundations on which to build theory in this way are sparse and weak.

2] The acceptance or rejection of a theoretical idea is unrelated to the specific purpose or purposes for which it is to be used. A theory is or is not logically consistent with the data; such logical consistency is the sole criterion for acceptance. 
On Teaching Demography: Some Non-Traditional Guidelines

Some social scientists have come to see logical empiricism as a frustrating and self-defeating approach. Not a few philosophers of science have argued, and some physical scientists have testified on their own behalf, that logical empiricism does not describe how they actually work. Roger Newton, writing about Isaac Newton's laws, comments '...Newton's laws of motion are not simply inductive consequences of observations but are products of a very fertile imagination' [Newton, 1997, p.15].

\section{An Alternative to Logical Empiricism}

An alternative view is found in many quarters but is not the mainstream view, certainly not in contemporary demography. Theoretical economics provides a partial departure from the above characterisation of logical empiricism. Its central theory is derived from axioms, but its development and range have been cramped by rigid adherence to a limited axiom set. The political scientist Eugene Meehan outlined an alternative approach as early as 1968 [Explanation in Social Science: A System Paradigm]. Nathan Keyfitz did much the same in his 1975 paper 'How do we know the facts of demography?' Hedstrom and Swedberg [1998] have advocated a return to 'middle-range' analytic theory, again in an approach that departs sharply from logical empiricism.

An influential school of contemporary philosophy of science [the 'semantic' school] has elaborated ideas similar to those of the authors just mentioned. An accessible and authoritative work is by Ronald Giere [1999]. Giere call this alternative view a 'model-based' view of science. For Giere, the prototype of scientific knowledge is not the scientific law, but the theoretical model plus a list of cases to which it applies. In this approach, a theory or theoretical model - the distinction is seen largely as one of scope - is constructed in such a way that it is formally true, in Giere's words 'true in the same way that a definition is true.' The model consists of clear concepts with well-specified relations among them, forming a logically consistent and coherent system. It is this clarity and coherence that yields a model's analytic power. The empirical question, then, is not whether a model is true or false, valid or invalid - it is true by definition. The relevant empirical question is whether it fits some empirical phenomenon, some well-described part of the real world a] closely enough b] in certain respects c] to be useful for some well-defined purpose - prediction, explanation, intervention and control, and - especially relevant to today's topic -- teaching. If a model does not meet all three of these criteria, then it is not used, but it also is not rejected as a theoretical model that may well be useful in other contexts 
Thomas K. Burch

for other purposes. If it fits well enough, then it is considered acceptable for the purpose at hand.

Theory is viewed not as Truth, but as an analytical tool. Taken as a whole it constitutes a toolbox of many theoretical models, some simple, some complex, some useful for one purpose, another for other purposes. It is these tools, so long as they are fashioned with clarity, rigour and logical consistency that give theory its analytical, predictive, and explanatory power.

Where do data and empirical research fit in? Empirical work is needed first of all the to give an accurate description of some phenomenon or some portion of the real world. Secondly, it is needed to test how well one or more of the seemingly relevant theoretical models fits that portion of reality -goodness of fit, but in a much broader sense than in statistical modelling. Finally, if broad empirical generalisations on the topic at hand exist, there is nothing to prevent their incorporation into the model itself.

In this model-based approach, theory is a response to empirical data, but is not derived from and therefore limited by data. The construction of theoretical models is an act of creative imagination.

In this view, demographic transition theory, especially if it were stated more rigorously, would be seen as a perfectly good and useful theoretical model, even though it does not fit some cases [e.g., France] very well, in respect to the relative timing of fertility and mortality decline. But it fits a large number of historical cases well enough for us to assert with confidence, for example, that any highly developed human society [by the conventional definitions of development] will have low fertility.

\section{Questioning the Formal/Behavioural Distinction}

This view of scientific theory has many implications for how we view and teach demography. One of the most important is that it erases the traditional sharp distinction between formal demography and population studies, based on the distinction between necessary and contingent relationships. With respect to theory, in the model-based view, all theoretical models and theories are formal, that is, true by definition.

It is customary in demography to consider formal demographic models as expressions of necessary relationships, for example, the fundamental demographic equation, or the stable model. Behavioural models such as transition theory or microeconomic models of demographic behaviour are seen 
as involving contingent relationships, which must therefore be tested against data.

In the model-based view, however, a behavioural model can and must be stated in such a way that it is formally and necessarily true. The logistic model of population growth, for example, assumes linear relationships between population density and both mortality and fertility. The classic transition model assumes strong relationships between development and both mortality and fertility. These relationships can be precisely specified, even if they seldom are. Are the relations between density and birth and death rates, or between development and birth and death rates necessary or contingent? The answer is that they are contingent in the real world, but necessary in the model - assumed, given, defined, true in the way that definitions are true.

Thus, the exponential equation $-\mathrm{P}[\mathrm{t}]=\mathrm{P}[0] \mathrm{e}^{\mathrm{rt}}$ is a theoretical model, a formal representation of the inherent nature of the growth of a biological population. No one would question the validity of this functional definition. Empirically it may or may not provide an accurate account of real world populations; over some specified period, some populations may grow approximately exponentially. But for many populations the model will not be even close. By this same reasoning, the life-table or the cohort-component projection models can be seen as theoretical models of population dynamics, as well as a measure of mortality and a forecasting tool respectively.

On the other hand, a simplified version of the Easterlin economic model of fertility and fertility control can be stated in such a way that it is true by definition:

\section{Definitions:}

-> Motivation $=$ expected minus desired surviving children

$->$ Costs $=$ money, time, effort, and 'psychic' costs

$\{->$ IF motivation > costs of control, THEN fertility control will occur;

$\{->$ IF motivation $\leq$ costs of control, THEN fertility control will not occur.

The brackets suggest what is in fact the case, that this is a definition of a function, although not yet a mathematical function [although it could be developed into one]. The model is true by definition and therefore completely general. Whether it applies to any particular real-world system is an empirical question. 
Thomas K. Burch

By this same reasoning, many other behavioural models in demography can be stated in such a way that they are formally true - transition theory, Lee's model of migration, Hernes' model of first marriage, and Coale-Hoover's model of population and development, to give only a few familiar examples.

One of the advantages of this perspective is that many older, simpler models often discarded or neglected - are seen as potentially valuable tools.

\section{Concluding Comment}

There is a paradox in all of this. Demographic technique is elevated to the status of theory, while theory is downgraded from TRUTH to an analytic tool, a thinking technique.

But as argued by Nathan Keyfitz, this model-based approach may offer a better way to advance demography as a science. To be faithful to the spirit of the model-based view, of course, we must not advance it as the only useful model of how science works or should work. There may be scientific laws [universal empirical generalisations] even in the social and behavioural sciences, so that, there may be topics for which the logical-positivist approach to theory and explanation will work. But for demography now, I suggest that a model-based view will provide a liberating and more fruitful approach to theory, modelling, and demographic explanation. It also has many implications for the teaching of demography, some of them at odds with current practice. I have discussed these at length elsewhere [Burch, 2001a and 2001b], and shall only summarise here by appending a statement of ten principles for teaching basic demography. These principles or guidelines are suggested by the approach to scientific methodology sketched above. They also are consistent with pedagogical practice in welldeveloped physical sciences, notably physics. Several of them correspond closely to the characteristics of teaching in the physical sciences outlined by Stephan and Massey [1982] in their thought-provoking paper on teaching undergraduate sociology. 
On Teaching Demography: Some Non-Traditional Guidelines

\section{Ten Principles for Teaching Basic Demography}

1] Put more emphasis on theory, that is, abstract models of population dynamics and demographic behaviour. Teach demography as a body of theoretical knowledge, as well as a body of data, techniques, and descriptive findings.

2] Retain and develop older and simpler - even 'oversimplified' - models insofar as they contain valuable insights that can help students begin to understand how populations work.

3] Put more emphasis on student activity - getting them to use the theoretical models that have been learned to solve real-world [or at least realistic] problems and exercises. The goal is the development of the student's ability to reason demographically, to explain, predict, or suggest policy interventions.

4] Set problems and exercises that lead students to face the limitations of available models, and to try to construct better ones.

5] Require students to have or to learn the tools needed for rigorous reasoning in the use of analytic models. The classic tool is mathematics. A more flexible and accessible tool for many demography students [notably in sociology departments] is some form of computer modelling.

6] Integrate 'formal demography' or 'techniques' with 'substantive' or 'behavioural demography' in the same course, rather than in distinct courses.

7] The basic principles of 'formal' demography must be taught or assumed in every demography course. Otherwise, it is not a demography course.

8] For efficiency and understanding, teach the most basic and general principles first. For example, subsume many of the standard demographic measures under the concepts of weighted sums or averages. For another example, present $\mathrm{e}_{0}$, TFR and the singulate mean age at marriage as based on the notion of area under some curve, not as three totally disparate measures.

9] For beginning students, put less emphasis on data collection, errors in data, and the most precise techniques. This is not a counsel of sloppiness. It is not sound pedagogy to immerse students in data-collection techniques and discouraging claims about errors, at the expense of theoretical ideas.

10] Since relatively simple theoretical models lend themselves to visual representation, use more diagrams in texts and lectures. Use visual representation for ideas, not just for graphing data. 
Thomas K. Burch

\section{End Notes:}

This is a revised version of a paper, "Teaching the Fundamentals of Demography: A Models-based Approach," presented at a panel session on teaching demography organized by Frank Trovato held during the meetings of the Canadian Population Society, Quebec City, Quebec, 29 May 2001.

\section{References:}

Burch, Thomas K. 1996. "Icons, strawmen and precision: reflections on demographic theories of fertility decline," The Sociological Quarterly 37:59-81.

Burch, Thomas K. 2001a. Teaching the fundamentals of demography: a modelbased approach to family and fertility. Paper presented at IUSSP Seminar on Demographic Training for the Third Millennium, Rabat, Morocco, 15-18 May 2001.

Burch, Thomas K. 2001b. Teaching demography: ten principles and two rationales. Paper presented at Session S65 on Teaching Demography [Chair, Graziella Caselli] at the IUSSP XXIV General Population Conference, Salvador, Brazil, 18-24 August 2001.

Giere, Ronald N. 1999. Science Without Laws. Chicago: University of Chicago Press.

Hedstrom, Peter. and Swedberg, Richard. 1998. Social Mechanisms: An Analytic Approach to Social Theory. Cambridge: Cambridge University Press.

Keyfitz, Nathan. 1975. "How do we know the facts of demography?" Population and Development Review 1:267-288.

Meehan, Eugene J. 1968. Explanation in Social Science: A System Paradigm. Homewood, Ill.: The Dorsey Press.

Newton, Roger. 1997. The Truth of Science: Physical Theories and Reality. Cambridge, MA: Harvard University Press.

Stephan, G. Edward; and Massey, Douglas. 1982. "The undergraduate curriculum in sociology: an immodest proposal," Teaching Sociology 9: 423-434. 